\title{
Structure feature of ternary state diagrams of Cr-Ti-V and Cr-Mn-V systems
}

\author{
Anatoliy Klopotov ${ }^{1,2 *}$, Irina Kurzina ${ }^{1}$, Alexander Potekaev ${ }^{1}$, Artem Ustinov $^{1,2}$, Taras Dement ${ }^{1,2}$, \\ Ludmila Kazantseva ${ }^{1}$, Ekaterina Marchenko ${ }^{1}$, and Natalia Karakchieva ${ }^{1,3}$ \\ ${ }^{1}$ National Research Tomsk State University, 634050, Tomsk, Russia \\ ${ }^{2}$ Tomsk State University of Architecture and Building, 634003,Tomsk, Russia \\ ${ }^{3}$ Siberian Research Institute of Agriculture and Peat - branch of the Siberian Federal Scientific Center of \\ Agro Bio Technologies of the Russian Academy of Sciences, 634050, Tomsk, Russia
}

\begin{abstract}
This paper presents the research results of features of structural and phase states in Cr$\mathrm{Ti}-\mathrm{V}$ and $\mathrm{Cr}-\mathrm{Mn}-\mathrm{V}$ systems based on analysis of crystal-geometric and crystal-chemical factors. The diagrams of isothermal sections of state diagrams of $\mathrm{Cr}-\mathrm{Ti}-\mathrm{V}$ and $\mathrm{Cr}-\mathrm{Mn}-\mathrm{V}$ systems were built in coordinates of the electron number $(\mathrm{s}+\mathrm{d})$ per atom with homogeneity regions of solid solutions and intermetallic compounds. It was shown that in the Cr-Ti-V system, addition of $\mathrm{Mn}$ atoms leads to substantial extension of the existence domain of the disordered solid solution based on the BCC lattice.
\end{abstract}

\section{Introduction}

At present, approaches aimed at creation of materials resistant to radiation embrittlement are being developed in metallophysics. This is related to the fact that in reactor construction, a strategy in creation of materials for the operation of reactor plants of VVEP type throughout 60 years was developed [1]. Solution of this task is connected to creation of structural materials resistant to radiation exposure. This class of materials includes Cr-Ti-V-based alloys [2-5]. Therefore, research on the study of peculiarities of structural and phase states based on analysis of crystal-geometric parameters in solid solutions and intermetallic compounds in the $\mathrm{Cr}-\mathrm{Ti}-\mathrm{V}$ system is of importance. Creation of metallic multicomponent high-entropic alloys (HEAs) based on Cr-Ti-V alloys is of interest from the standpoint of creation of radiation-resistant materials. This is related to the fact that high-entropic alloys possess delayed diffusion of element atoms, which is accompanied by their cooperative transition. This phenomenon impedes the decomposition of substitutional solid solutions and prevents from creation of new phases [6-8]. The composition of alloys of this class includes heterogeneous atoms of elements with a different electronic structure, sizes and thermodynamic properties. The number of elements, included in high-entropic alloys, is usually about 5-10. At the same time, in the burdening composition, they are usually in the equiatomic ratio. Such chemical composition contributes to substantial distortion of the crystal lattice of alloys $[7,8]$. In these alloys, high entropy of mixing of elements is considered as a measure of probability of preserving their structural and phase state in [9-11]. In high-entropic alloys, the presence of a set of mentioned factors contributes to increased thermal stability of structural and phase states and, as a consequence, of high mechanical, physical and chemical properties [9-11]. The composition of multicomponent high-entropic alloys usually includes elements which are within the 4th and 5 th periods of the Periodic system of elements (Ti, V, $\mathrm{Cr}, \mathrm{Mn}, \mathrm{Fe}, \mathrm{Co}, \mathrm{Ni}, \mathrm{Cu} \mathrm{Zr}, \mathrm{Nb}$ and $\mathrm{Mo}$ ) with valence (sd)-electrons. Therefore, in the framework of the approach, transformation of alloys in the $\mathrm{Cr}-\mathrm{Ti}-\mathrm{V}$ system in high-entropic alloys, it is of interest to research what influence additional $\mathrm{Mn}$ alloying can exert on structuralphase states of one-phase alloys $(\mathrm{Cr}, \mathrm{Mn}, \mathrm{Ti}, \mathrm{V}$,) in a disordered state based on the BCC lattice. Earlier to search for regularities when studying peculiarities of structural and phase states in binary and ternary systems, the authors used an approach based on analysis of crystal-geometric and crystal-chemical characteristics of metallic compounds and solid solutions [12-15]. The purpose of this paper is to present the results of researching the features of structural and phase states in ternary $\mathrm{Cr}-\mathrm{Ti}-\mathrm{V}$ and $\mathrm{Cr}-\mathrm{Mn}-\mathrm{V}$ systems based on the analysis of binary state diagrams, forming them, and crystal-geometric and crystal-chemical factors.

\section{Methods and Materials}

To search of the regularities of structural and phase states in binary and ternary systems, the authors used an approach based on analysis of crystal-geometric and crystal-chemical characteristics of metallic compounds and solid solutions [12-15]. It was investigated the state

'Corresponding author: klopotovaa@tsuab.ru 
diagram of $\mathrm{Cr}-\mathrm{Ti}$, Cr-V, Ti-Cr, Cr-Mn, Cr-V, Mn-V, $\mathrm{Cr}-\mathrm{Ti}-\mathrm{V}$ and $\mathrm{Cr}-\mathrm{Mn}-\mathrm{V}$ systems.

\section{Results and Discussion}

\subsection{State diagram of $\mathrm{Cr}-\mathrm{Ti}, \mathrm{Cr}-\mathrm{V}$, Ti-Cr, Cr-Mn, $\mathrm{Cr}-\mathrm{V}, \mathrm{Mn}-\mathrm{V}, \mathrm{Cr}-\mathrm{Ti}-\mathrm{V}$ and $\mathrm{Cr}-\mathrm{Mn}-\mathrm{V}$ systems}

A peculiarity of the binary and ternary systems under consideration is conditioned by the electronic structure of alloy-forming elements and a dimensional factor. The electronic structure and the structure of alloy-forming elements and their crystal structures in these systems are given in the Table 1.

Table 1. The electronic structure and the structure of alloyforming elements in Cr-Ti-V and Cr-Mn-V systems.

\begin{tabular}{|c|c|c|c|c|c|}
\hline$\stackrel{\pi}{\stackrel{\pi}{0}}$ & 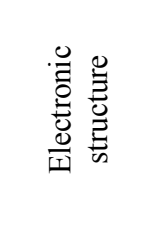 & $\begin{array}{l}\grave{0} \\
\frac{0}{\pi} \\
>\end{array}$ & $\begin{array}{l}\Xi \\
\simeq \\
\simeq\end{array}$ & 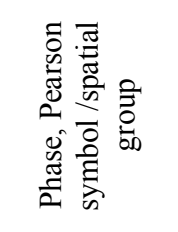 & 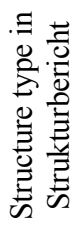 \\
\hline $\mathrm{Ti}$ & {$[\mathrm{Ar}] 3 \mathrm{~d}^{2} 4 \mathrm{~s}^{2}$} & 4 & 0.1462 & $\begin{array}{c}\beta-\mathrm{Ti}, c 12 / \\
\operatorname{Im} 3 m \\
\alpha-\mathrm{Ti}, h P 2 / \\
P 6_{3} / m m c\end{array}$ & $\begin{array}{l}\text { A2 } \\
\text { A3 }\end{array}$ \\
\hline V & {$[\mathrm{Ar}] 3 \mathrm{~d}^{3} 4 \mathrm{~s}^{2}$} & 5 & 0.1346 & $\begin{array}{c}c I 2 / c I 2 / \\
\operatorname{Im} 3 m\end{array}$ & $\mathrm{~A} 2$ \\
\hline $\mathrm{Cr}$ & {$[\operatorname{Ar}] 3 \mathrm{~d}^{5} 4 \mathrm{~s}^{1}$} & $\begin{array}{l}3 \\
6\end{array}$ & $\begin{array}{l}0.1360 \\
0.1282\end{array}$ & $c I 2 / \operatorname{Im} 3 m$ & $\mathrm{~A} 2$ \\
\hline $\mathrm{Mn}$ & {$[\mathrm{Ar}] 3 \mathrm{~d}^{5} 4 \mathrm{~s}^{2}$} & $\begin{array}{l}4 \\
6\end{array}$ & $\begin{array}{l}0.1360 \\
0.1264\end{array}$ & $\begin{array}{c}\alpha \mathrm{Mn}, I 43 m / \\
c I 58 \\
\beta \mathrm{Mn}, \\
P 4_{1} 32 / c P 20 \\
\gamma \mathrm{Mn}, \\
F m 3 m / c F 4 \\
\delta \mathrm{Mn}, c I 2 / \\
I m 3 m\end{array}$ & $\begin{array}{c}\text { A12 } \\
\text { A13 } \\
\text { A1 } \\
\text { A2 }\end{array}$ \\
\hline
\end{tabular}

\section{Ti-V system}

In the Ti-V system, it was established that the solid solution $(\beta \mathrm{Ti}, \mathrm{V})$ with the content of $30-50$ at. $\% \mathrm{~V}$ is unstable. This phenomenon manifests itself during decay into two isomorphic solutions based on $(\beta \mathrm{Ti})$ and $(\mathrm{V})$ after annealing at $500{ }^{\circ} \mathrm{C}$ and long-term soakings for about 300 hours [16]. It was established that solubility of $\mathrm{V}$ in $(\alpha \mathrm{Ti})$ is of retrograde nature, reaching the values of $3.7 \div 3.8$ at. $\% \mathrm{~V}$ at $500 \div 600{ }^{\circ} \mathrm{C}$ and decreasing to 2.5 at. $\% \mathrm{~V}$ at $400{ }^{\circ} \mathrm{C}$. In the $\mathrm{Ti}-\mathrm{V}$ system, the existence of monotectoid transformation in the alloys of the $\mathrm{Ti}-\mathrm{V}$ system at $675^{\circ} \mathrm{C}$ was established. The temperature of the critical point of layering curve corresponds to $850{ }^{\circ} \mathrm{C}$ with a monotectoid point at 18 at. $\%$. The $(\alpha \mathrm{Ti})-$ based solid solution amounts to 2.7 at. $\% \mathrm{~V}$. The monotectoid horizontal extends to 80 at. $\% \mathrm{~V}$. The minimum within 34 at. $\% \mathrm{~V}$ is observed on the meltability curve.

\section{Cr-V system}

The Cr-V system (Figure 1) is characterised by unlimited solubility of components in solid and liquid states. In the $\mathrm{Cr}-\mathrm{V}$ system, on the liquidus curve there is a minimum within 30 at. $\% \mathrm{~V}$ and the temperature of $1767^{\circ} \mathrm{C}$ [16].

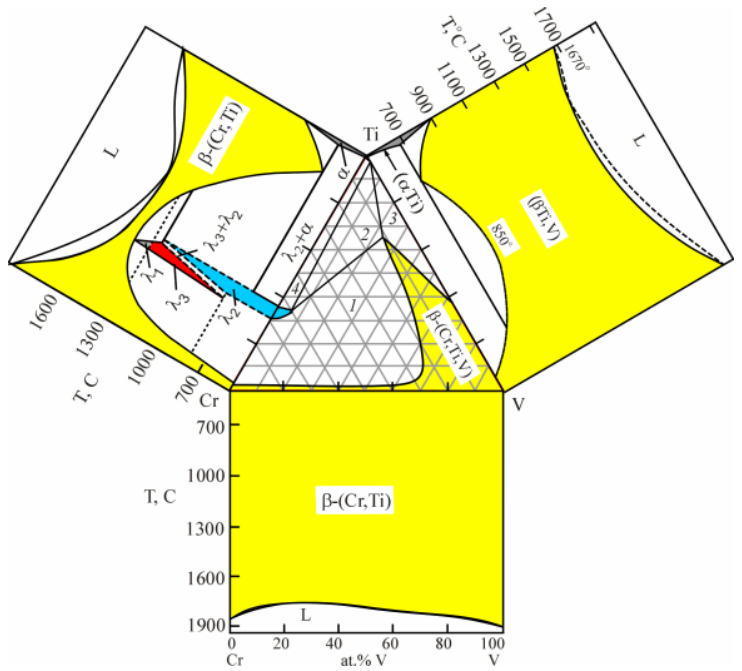

Fig. 1. Binary state diagrams of $\mathrm{Cr}-\mathrm{Ti}, \mathrm{Cr}-\mathrm{V}$, Ti-V systems [17] and isothermal sections of the ternary $\mathrm{Cr}-\mathrm{Ti}-\mathrm{V}$ system at the temperature of $500^{\circ} \mathrm{C}$. Figures denote two-phase and threephase regions in isothermal triangle $\mathrm{Cr}-\mathrm{Ti}-\mathrm{V}: 1-\lambda_{2}+\beta-$ $(\mathrm{Cr}, \mathrm{Ti}, \mathrm{V}) ; 2-\lambda_{2}+\alpha+\beta-(\mathrm{Cr}, \mathrm{Ti}, \mathrm{V}) ; 3-\alpha+\beta-(\mathrm{Cr}, \mathrm{Ti}, \mathrm{V}) ; 4-\lambda_{2}+\alpha$ [18].

\section{Cr-Ti system}

On the phase diagram of the Ti-Cr system, there is a continuous dissolution of titanium and chromium in the liquid state accompanied by formation of solid solutions $(\beta-\mathrm{Ti}, \mathrm{Cr})$ in the wide homogeneity region. The main transformations in the $\mathrm{Ti}-\mathrm{Cr}$ system occur in a solid state. In the region of the $\mathrm{TiCr}_{2}$ composition, intermediate phases are formed with a structure of Laves phases $\mathrm{C} 14$ (prototype - $\left.\mathrm{MgZn}_{2}\right), \mathrm{C} 15\left(\mathrm{MgCu}_{2}\right)$ and $\mathrm{C} 36$ $\left(\mathrm{MgNi}_{2}\right)$. The high-temperature modification of Laves phases C36 $\left(\lambda_{1}\right)$ forms congruently from the solid solution $(\beta-\mathrm{Ti}, \mathrm{Cr})$ at a temperature of $1370^{\circ} \mathrm{C}$.

With the temperature decrease below $1270{ }^{\circ} \mathrm{C}$, hightemperature phase C36 $\left(\lambda_{1}\right)$ transforms into mediumtemperature Laves phase $\mathrm{C} 14\left(\lambda_{2}\right)$. The low-temperature modification of Laves phase $\mathrm{C} 15\left(\lambda_{3}\right)$ forms according to a peritectoid reaction from Laves phase C14 $\left(\lambda_{2}\right)$ and from $(\beta-\mathrm{Ti}, \mathrm{Cr})$ at a temperature of $\sim 1220{ }^{\circ} \mathrm{C}$. In the Ti$\mathrm{Cr}$ system, there are two eutectoid reactions of decay of the solid solution $(\beta-\mathrm{Ti}, \mathrm{Cr})$ and Laves phase $\mathrm{C} 14$ $[16,17]$.

\section{Cr-Mn system}

In the Cr-Mn system, manganese allotropy complicates the state diagram on the part of manganese. Existence of different polymorphic forms of crystal structures based on $\mathrm{Mn}((\alpha \mathrm{Mn}),(\beta \mathrm{Mn}),(\gamma \mathrm{Mn})$ and $(\delta \mathrm{Mn}))$, a wide homogeneity region of the solid solution based on $\mathrm{Cr}$ 
and two intermediate phases $\alpha\left(\mathrm{CrMn}_{2}\right)$ and $\sigma\left(\mathrm{CrMn}_{3}\right)$ were revealed [16].

\section{Cr-Ti-V system}

Figure 1 presents an isothermal section of the $\mathrm{Cr}-\mathrm{Ti}-\mathrm{V}$ system at $500{ }^{\circ} \mathrm{C}[18]$. On the isothermal triangle in this system, one vast region of a three-component solid solution, based on the disordered BCC lattice, can be easily revealed: $\beta-(\mathrm{Cr}, \mathrm{Ti}, \mathrm{V})$. In the base of formation of this region, there is a binary system, the components of which are miscible in all proportions in each other. The size of the region of the three-component solid solution $(\mathrm{Cr}, \mathrm{Ti}, \mathrm{V})$ is limited by the extent of corresponding regions of solid solutions in binary systems $\mathrm{Cr}-\mathrm{Ti}$ and $\mathrm{Ti}-\mathrm{V}$. Along the $\mathrm{Ti}-\mathrm{V}$ side of the isothermal triangle, this region is limited by the concentration to $\sim 40$ at. $\% \mathrm{~V}$. On the $\mathrm{Cr}$-Ti side of the isothermal triangle, there is a bounded region of ternary compounds based on Laves phases. Also inside the isothermal triangle, there is vast two-phase region from Laves phase $\lambda_{2}$ and solid solution $\beta-(\mathrm{Cr}, \mathrm{Ti}, \mathrm{V})$.

In [19], it is shown that one of the main factors influencing the stability of the structural and phase state of alloys is their electronic structure. A parameter that characterises the electronic structure of alloys is electronic concentration. At the same time, according to [19], the electronic concentration of the alloy depends on the electronic structure of alloy-forming elements. Therefore, to analyse it, the authors use isothermal sections of state diagrams of ternary systems in coordinates of the number of electrons $(s+d)$ per atom (Figure 2). The value of electronic concentration $(\mathrm{s}+\mathrm{d})$ of alloy electrons was calculated as an arithmetic mean value of valence electrons of all individual alloy-forming elements.

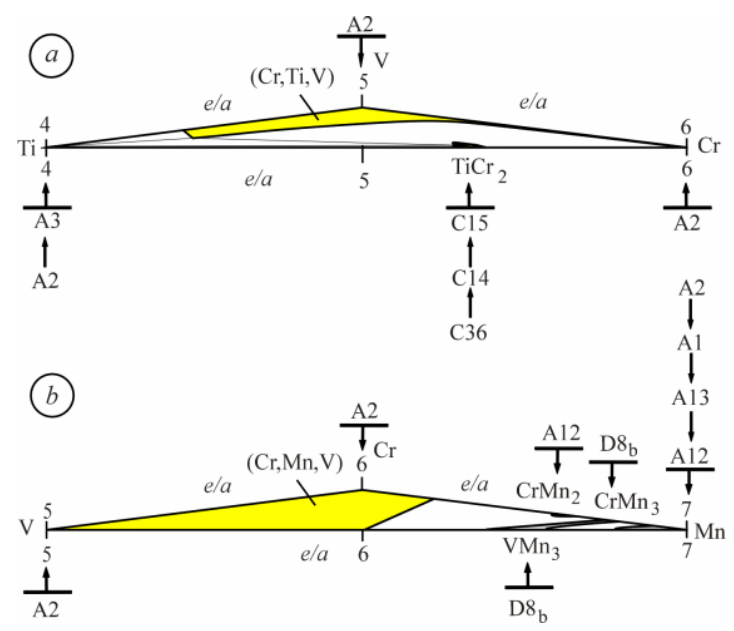

Fig. 2. Isothermal sections of state diagrams of Cr-Ti-V (a) and $\mathrm{Mn}-\mathrm{Ti}-\mathrm{V}$ (b) systems in coordinates of the number of $(\mathrm{s}+\mathrm{d})$ electrons per atom with homogeneity regions of solid solutions and intermetallic compounds. Classification of structures in the diagram is given according to Strukturbericht.

In the Cr-Ti-V system, in the vast region of values of electronic concentration from 4.4 to 6 electron/atom, there is a bounded region of the unbounded three- component solid solution $(\mathrm{Cr}, \mathrm{Ti}, \mathrm{V})$ based on the disordered BCC lattice with the A2 structure (Figure 2).

In Figure 2, the diagram shows that in the $\mathrm{Ti}-\mathrm{Cr}$ system in the concentration region of 5.3 electron/atom, Laves phases form in different temperature ranges (Figure 1). At the same time, addition of $\mathrm{V}$ atoms suppresses Laves phases' formation.

\section{Cr-Mn-V system}

The isothermal section of the ternary $\mathrm{Cr}-\mathrm{Mn}-\mathrm{V}$ system is given in Figure 3 at a temperature of $25{ }^{\circ} \mathrm{C}$ [20].

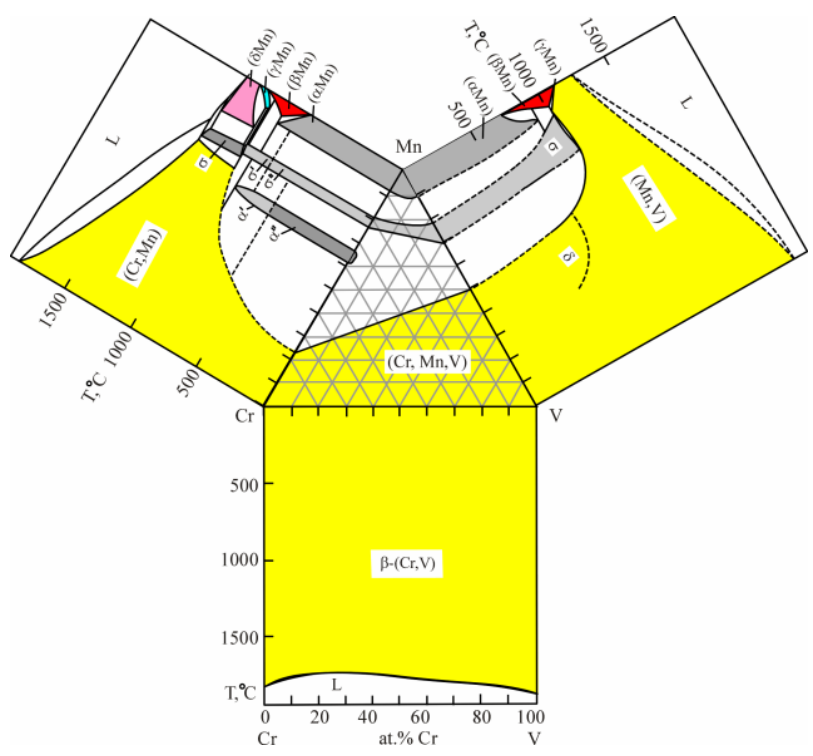

Fig. 3. Binary state diagrams of $\mathrm{Cr}-\mathrm{Mn}, \mathrm{Cr}-\mathrm{V}, \mathrm{Vn}-\mathrm{V}$ systems [16] and isothermal section of the ternary $\mathrm{Cr}-\mathrm{Mn}-\mathrm{V}$ system at the temperature of $25^{\circ} \mathrm{C}$ [20].

In this system, two regions with well-defined regions of homogeneity manifest themselves vividly. This is a region of the three-component solid solution $(\mathrm{Cr}, \mathrm{Mn}, \mathrm{V})$ based on the disordered BCC lattice, which occupies a significant part of the isothermal triangle and leans on the $\mathrm{Cr}-\mathrm{V}$ side of the isothermal triangle. Another region belongs to the three-component compound with a $\sigma$ phase structure $(t P 30, P 42 / \mathrm{mnm}$, prototype $\sigma \mathrm{CrFe})$. The three-component intermetallic compound of the $\sigma$-phase has a narrow homogeneity region and forms based on binary compounds on two sides $\mathrm{Cr}-\mathrm{Mn}$ and $\mathrm{Mn}-\mathrm{V}$ of the isothermal triangle based on binary compounds $\mathrm{CrMn}_{3}$ and $\mathrm{CrV}_{3}$ (Figure 3 ).

The diagram in Figure 2 shows that in the Cr-Mn-V system in the concentration region from 5 electron/atom to 6.2 electron/atom, there is a disordered solid solution (Cr, Mn, V).

Replacement of $\mathrm{Ti}$ atoms by $\mathrm{Mn}$ atoms during transition from the $\mathrm{Cr}-\mathrm{Ti}-\mathrm{V}$ system to the $\mathrm{Cr}-\mathrm{Mn}-\mathrm{V}$ system extends substantially the region of existence of the disordered solid solution based on the BCC lattice in the $(\mathrm{Cr}, \mathrm{V}) \mathrm{Mn}_{3}$ alloys. In $(\mathrm{Cr}, \mathrm{V}) \mathrm{Mn}_{3}$ alloys the electronic concentration of $6.6-6.8$ electron/atom, leads to formation of the three-component region of existence of the $\sigma$-phase with the $D 8_{\mathrm{b}}$ structure (Figure 2, b). 
In the $\mathrm{Cr}-\mathrm{Mn}-\mathrm{V}$ systems with electronic concentration values from 4.4 to 6 electron/atom, there is a region of the unbounded three-component solid solution $(\mathrm{Cr}, \mathrm{Mn}, \mathrm{V})$ based on the disordered BCC lattice with the A2 structure (Figure 2). A three-component compound with the $\sigma$-phase structure in the form of a narrow homogeneity region forms on two sides $\mathrm{Cr}-\mathrm{Mn}$ and $\mathrm{Cr}-\mathrm{V}$ of the isothermal triangle with the electronic concentration of $6.6 \div 6.8$ electron/atom.

Compounds with the $\sigma$-phase possess wide and narrow regions of homogeneity [21]. The uniqueness of the $\sigma$-phase consists in the fact that this phase has no strict stochiometric composition and this manifests itself by the presence of different stochiometric compositions in this phase: $\mathrm{AB}(\mathrm{FeV}), \mathrm{A}_{2} \mathrm{~B}\left(\mathrm{Mn}_{2} \mathrm{Mo}\right), \mathrm{A}_{3} \mathrm{~B}\left(\mathrm{Mn}_{3} \mathrm{Cr}\right)$ and $\mathrm{A}_{4} \mathrm{~B}\left(\mathrm{Mn}_{4} \mathrm{~V}\right)$. The formation processes and stability of compounds with the $\sigma$-phase are influenced by dimensional and electronic factors. On the one hand, the decisive role belongs to the dimensional factor, on the other - to the electronic factor [22]. With the change in the electronic concentration, the composition of this phase changes from $A_{3}$ to $A_{2} B$. The $\sigma$-phase formation is also significantly influenced by the electronic configuration of forming components [23].

\subsection{Crystal-geometric and thermodynamic factors and features of state diagrams of $\mathrm{Cr}-\mathrm{Ti}-\mathrm{V}$ and $\mathrm{Cr}-\mathrm{Mn}-\mathrm{Ti}$ systems}

To search for common regularities when analysing the state diagrams of the systems, dimensional $(\delta)$ and entropic (nS) factors were used [13-14, 24].

The dimensional factor was determined by the formula by means of the expression:

$$
\delta=1-R_{B} / R_{A} \text {, }
$$

where $R_{A}$ and $R_{B}-$ atom radii of grade $A$ and $B$.

The role of the relative sizes of atoms when forming structural and phase states in ternary systems Cr-Ti-V and $\mathrm{Cr}-\mathrm{Mn}-\mathrm{Ti}$ was determined by means of diagrams shown in Figure 4. According to Hume-Rothery [25, 26], formation of unbounded solid solutions is possible with dimensional factor $\delta<0.15$. The dimensional factor was determined by the formula using expression $\delta=1-\mathrm{R}_{\mathrm{B}} / \mathrm{R}_{\mathrm{A}}$ $\left(R_{A}\right.$ and $R_{B}$ - atom radii of grade $A$ and $B$ ). These diagrams show that the dimensional factor is favourable for formation of unbounded solid solutions in the systems under consideration. Nevertheless, in the Cr-Ti, $\mathrm{Cr}-\mathrm{Mn}$ and $\mathrm{Mn}-\mathrm{V}$ systems, there is formation of compounds from disordered solid solutions, and decay is observed in the Ti-V system.

Of the two ternary systems Cr-Ti-V and Cr-Mn-Ti, the $\mathrm{Cr}-\mathrm{Mn}-\mathrm{Ti}$ system is the most favourable for formation of unbounded solid solutions. This is reflected in more extensive regions of unbounded solid solutions in isothermal triangles (Figure 1-3). Therefore, additional alloying of alloys of the Cr-Ti-V system by $\mathrm{Mn}$ atoms in the vanadium angle of the isothermal triangle enables extension of the region of fourcomponent unbounded solid solutions ( $\mathrm{Cr}, \mathrm{Mn}, \mathrm{Ti}, \mathrm{V})$.

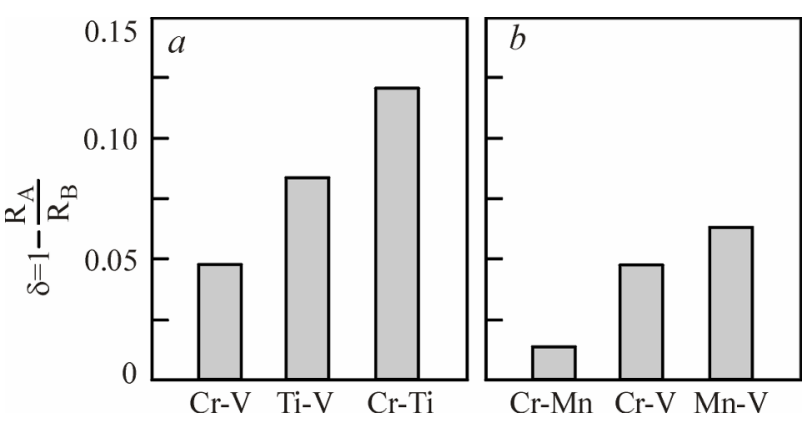

Fig. 4. Diagrams, reflecting contributions of the dimensional factor in binary systems into the sizes of the homogeneity regions of solid solutions in ternary $\mathrm{Cr}-\mathrm{Ti}-\mathrm{V}$ (a) and $\mathrm{Cr}-\mathrm{Mn}-\mathrm{V}$ (b) systems.

As per the data given in the table 1 and conditions of formation of continuous series of solid solutions for metallic compounds, according to Hume-Rothery [25, 26], alloy formation in the considered systems leads to formation of unbounded regions of continuous solid solutions and this finds confirmation in the state diagrams (Figure 1).

The parameter that reflects the change in the bond type is the entropy of melting Smel [24]. Since the entropy of component melting reflects the destruction degree of the long-range order during a phase transition from solid solution to liquid, the elements and compounds with a valency bond have greater entropy of melting than the elements and compounds with a metallic bond. This parameter is applicable for the analysis of state diagrams of ternary systems $\mathrm{Cr}-\mathrm{Ti}-\mathrm{V}$ and $\mathrm{Cr}-\mathrm{Mn}-\mathrm{Ti}$.

The entropy factor was determined using the expression:

$$
\mathrm{nS}=\mathrm{S}_{\mathrm{A}} / \mathrm{S}_{\mathrm{B}}
$$

where $S_{A}$ and $S_{B}$ are entropies of melting of $A$ and $B$ elements.

Specific threshold values $n_{S}$, determining the opportunity of a certain type of interaction were defined in [24]. For ternary state diagrams, the condition of formation of unbounded solid solutions can be written in the form of the following inequalities:

$$
\begin{aligned}
& \mathrm{n}_{\mathrm{S} 1}=\mathrm{S}_{\mathrm{A}} / \mathrm{S}_{\mathrm{B}} \leq 1.10, \\
& \mathrm{n}_{\mathrm{S} 2}=\mathrm{S}_{\mathrm{A}} / \mathrm{S}_{\mathrm{C}} \leq 1.10, \\
& \mathrm{n}_{\mathrm{S} 3}=\mathrm{S}_{\mathrm{B}} / \mathrm{S}_{\mathrm{C}} \leq 1.10 .
\end{aligned}
$$

In this case $\mathrm{S}_{\mathrm{A}}, \mathrm{S}_{\mathrm{B}}$ and $\mathrm{S}_{\mathrm{C}}$ are entropies of elements $\mathrm{A}, \mathrm{B}$ and $\mathrm{C}$ accordingly.

The values of the entropy factor when forming structural-phase states in ternary systems $\mathrm{Cr}-\mathrm{Ti}-\mathrm{V}$ and $\mathrm{Cr}-\mathrm{Mn}-\mathrm{Ti}$ were determined by means of the diagrams shown in Figure 5.

The mentioned diagrams demonstrate that the entropic factor for the elements, forming the analysed systems, is less than the threshold value of 1.10 . Thus, in the ternary $\mathrm{Cr}-\mathrm{Ti}-\mathrm{V}$ and $\mathrm{Cr}-\mathrm{Mn}$ - Ti systems, the values of the entropy factor are within the limits that are favourable for formation of unbounded solid solutions in binary systems. But, nevertheless, intermediate phases form in the Cr-Ti, Cr-Mn, Mn-V systems, and in the Ti$\mathrm{V}$ system there is a decay into two isomorphic solutions. All this is evidence of significant influence of the 
electronic factor on stability of structural-phase states in these systems.

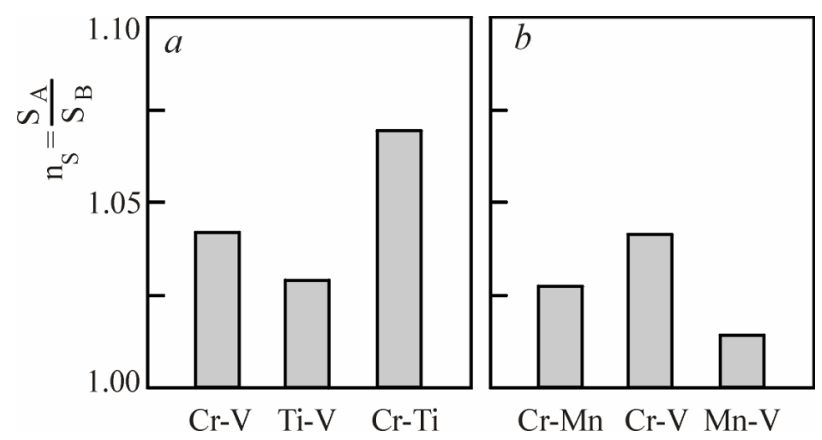

Fig. 5. Diagrams characterising the entropic factor in binary $\mathrm{Cr}-\mathrm{V}, \mathrm{Ti}-\mathrm{V}, \mathrm{Cr}-\mathrm{Ti}$ (a) and $\mathrm{Cr}-\mathrm{Mn}, \mathrm{Cr}-\mathrm{V}, \mathrm{Mn}-\mathrm{V}$ (b) systems.

The presence of intermediate phases in the $\mathrm{Cr}$ - $\mathrm{Ti}$, $\mathrm{Cr}-\mathrm{Mn}, \mathrm{Mn}-\mathrm{V}$ systems and the presence of decay into two isomorphic solutions in the Ti-V system are evidence of a significant influence of the electronic factor on the structural and phase states in alloys of these systems.

\section{Conclusion}

A search for correlations among the structure of state diagrams of binary systems, based on V-Me $(\mathrm{Me}=\mathrm{Cr}, \mathrm{Mn}, \mathrm{Ti})$, and ternary state diagrams $\mathrm{Cr}-\mathrm{Ti}-\mathrm{V}$ and $\mathrm{Cr}-\mathrm{Mn}-\mathrm{V}$, and crystal-geometric and crystalchemical parameters was carried out. It was established that only in the binary $\mathrm{Cr}-\mathrm{V}$ system, the main parameters exerting a dominating influence on the formation of unbounded regions of solid solutions, based on the disordered BCC lattice, are the dimensional and entropic parameters. In binary $\mathrm{Cr}-\mathrm{Ti}, \mathrm{Cr}-\mathrm{Mn}$, Ti-Mn systems and ternary $\mathrm{Cr}-\mathrm{Ti}-\mathrm{V}, \mathrm{Cr}-\mathrm{Mn}-\mathrm{V}$ systems, the influence of the electronic factor on the sizes of regions of unbounded solid solutions, based on the disordered BCC lattice, increases.

In one-phase alloys in the $\mathrm{Cr}-\mathrm{Ti}-\mathrm{V}$ system, it is possible to obtain increased thermal stability of the structural-phase composition by additional Mn alloying. It is necessary to note that transfer of meaning of disordered alloys $(\mathrm{Cr}, \mathrm{Mn}, \mathrm{Ti}, \mathrm{V}$,$) , based on the BCC$ lattice, to the class of multicomponent high-entropic alloys is possible owing to additional introduction of $\mathrm{Mn}$, as well as elements from IV, V and VI groups of Mendeleev's periodic system, into their composition.

This manuscript is performed with financial support of the Ministry of Education and Science of the Russian Federation. Grant agreement No RFMEFI57517X0123

\section{References}

1. G.P. Karzov, B.Z. Margolin, I.V. Teplukhina, V.A. Piminov, Probl. Mater Sci., 782 (2014)

2. H.M. Chung, B.A. Loomis, I.J. Nowicki, I.L.Smith Report DOE/ER-0313/14 (1993)
3. I.V. Borovitskaya, S.N. Korshunov, M.M. Lyakhovitsky, A.N. Mansurova, V.V. Paramonova, PAS\&T/TF, 36, 4 (2013)

4. L.S. Danelyan, S.N. Korshunov, A.N. Mansurova, V.V. Zatekin, V.S. Borovitskaya, L.I. Ivanov, V.V. Paramonova, M.M. Lyakhovitsky, PAS\&T/TF, 36, 4 (2013)

5. I.E. Lublinskiy, A.V. Vertkoe, V.A. Evtikhin, S.N. Votinov, I.N. Gubkin, Yu.V. Karasev, A.I. Dediurin, I.V. Borovitskaya, PAS\&T/TF, 3 (2005)

6. ShengGuo, C.T. Liu. Process in Natural Science: Materials International, 21 (2011)

7. Y. Zhang, T.T. Zuo, Z.Tang, M.C. Gao, K.A. Dahmen, P.K. Liaw, Z.P. Lu, Prog. Mater Sci., 61 (2014)

8. B.M. Daniel, D.M. Jonathan, O.N. Senkov, C. Woodward, D.U. Michael, J. Tiley, Entropy, 16 (2014)

9. J.W. Yeh, Y.L. Chen, S.J. Lin, S.K. Chen, Materials Science Forum, 560, (2007)

10. O.X. Senkov, J.M. Scott, S.V. Senkova, D.B. Miracle, C.F. Woodward, J. Alloys Compd., 509, 20 (2011)

11. Chun-Ming Lin, Chien-Chang Juan, Chia-Hsiu Chang, Che-Wei Tsai, Jien-Wei Yeh, J. Alloys Compd., 624 (2015)

12. A.Potekaev, S.Porobova, A.Klopotov, V.Vlasov, T.Markova, V. Klopotov, AIP Conference Proceedings. 1683 (2015)

13. M.M. Morozov, A.I.,Potekaev, A.A. Klopotov, V.V. Kulagina, T.N. Markova, V.D. Klopotov, Adv. Mat. Res. 1013 (2014)

14. E.A. Knestaypin, M.M. Morozov, A.I. Potekaev, A.A. Klopotov, T.N. Markova, V.D. Klopotov. AIP Conference Proceeding, 1623 (2014)

15. M.M. Morozov, A.I. Potekaev, A.A. Klopotov, T.N. Markova, V.D. Klopotov Metallic Alloys Steel in Translation, 45, 8 (2015)

16. A.I. Potekaev, A.A. Klopotov, S.A. Porobova, V.D. Klopotov, T.N. Markova, M.I. Imanaliev, Mater. Sci. Eng., 168 (2017).

17. N.P. Lyakisheva State diagrams of double metal systems(Mechanical engineering, Moscow, 19962000)

18. O.M. Barabash, Yu.N. Koval, Structure and properties of metals and alloys(Reference book. Crystal structure of metals and alloys, Naukova Dumka, Kiev, 1986)

19. G. Ghosh Journal of Phase Equilibria, 23, 4 (2002)

20. V.K. Grigorovich Periodic law of Mendeleev and the electronic structure of metals (Nauka, Moscow, 1966)

21. M. Brauwers, F. Brouers, Philosophical Magazine, 35 (1977)

22. J.M. Joubert, Progress in Materials Science, 53 (2008) 
23. N.M.Matveeva, E.V. Kozlov Ordered phases in metallic systems(Science, Moscow, 1989)

24. E.V.Kozlov, V.M.Dementev, N.M.Kormin, D.M. Shtern Structures and stability of ordered phases (TSU, Tomsk, 1994)

25. V.M. Vozdvizhinsky Forecast of double phase diagrams. By statistical criteria (Metallurgiya, Moskwa, 1972)

26. W.H. Hume-Rothery, G.Raynor Structure of metals and their alloys (Metallurgizdat, Moscow, 1958) 